\title{
Tidally induced turbulence and suspended sediment
}

\author{
Alejandro J. Souza \\ Proudman Oceanographic Laboratory, Liverpool, UK \\ Luis G. Alvarez \\ Departamento de Oceanografia Fisica, CICESE, Ensenada, Mexico \\ Tommy D. Dickey \\ Ocean Physics Laboratory, University of California, Santa Barbara, California, USA
}

Received 3 August 2004; accepted 22 September 2004; published 23 October 2004.

[1] Nearly continuous data collected using novel methods are utilized to advance the understanding of turbulence and suspended particulate matter (SPM) dynamics under strong tidal flow conditions. Key instrumentation includes a single acoustic current profiler that provides nearly continuous, concurrent turbulence and SPM information with respect to depth near the seafloor and within the water column. Observations show a lag of about 1 hour in turbulence production between the bottom and 12 meters above the bottom (mab), and of about 1.5 hours for SPM. Estimates of eddy viscosity show values ranging between $10^{-3}$ and $10^{-2} \mathrm{~m}^{2} \mathrm{~s}^{-1}$, with an almost constant mean value of $3.5 \times$ $10^{-3} \mathrm{~m}^{2} \mathrm{~s}^{-1}$ within the bottom 7 meters. The present observations and a previously reported theory show good agreement in both amplitude and phase for SPM and turbulence, when values of eddy viscosity ranging between $3.5 \times 10^{-3}$ (mean) and $10^{-2}$ (maximum) are used. Our data set is valuable for evaluating, developing, and improving turbulence and SPM numerical models. INDEX TERMS: 4568 Oceanography: Physical: Turbulence, diffusion, and mixing processes; 4219 Oceanography: General: Continental shelf processes; 4558 Oceanography: Physical: Sediment transport; 4594 Oceanography: Physical: Instruments and techniques; 4211 Oceanography: General: Benthic boundary layers. Citation: Souza, A. J., L. G. Alvarez, and T. D. Dickey (2004), Tidally induced turbulence and suspended sediment, Geophys. Res. Lett., 31, L20309, doi:10.1029/2004GL021186.

\section{Introduction}

[2] The present work was carried out in the Upper Gulf of California, which separates mainland Mexico from the Baja California Peninsula. Little freshwater now flows into the Upper Gulf, because of damming of the Colorado River in about 1930. Under the new regime, the Upper Gulf has been transformed into an evaporative basin with an annual evaporation rate of about $1 \mathrm{~m} \mathrm{yr}^{-1}$. This condition produces an inverse estuary effect during the summer months with resulting high temperatures $\left(>30.8^{\circ} \mathrm{C}\right)$, salinities $(>36.5)$ and SPM concentrations $\left(>20 \mathrm{mg}^{-1}\right)$; these conditions are particularly evident during neap tides [Alvarez and Jones, 2002].

[3] The Upper Gulf of California is a shallow region with water depths of less than $40 \mathrm{~m}$ with along-gulf ridges that

Copyright 2004 by the American Geophysical Union. 0094-8276/04/2004GL021186\$05.00 are about $30-40 \mathrm{~km}$ long and approximately $10-15 \mathrm{~m}$ high and lying above gently sloping troughs aligned with the Gulf's axis [Alvarez and Jones, 2002; Alvarez, 2003]. The seabed material consists of unconsolidated relic deposits from the Colorado River with silts distributed in the western part and sand-silts in the eastern side of the Gulf [Carriquiry and Sanchez, 1999].

[4] The Upper Gulf of California is the most energetic shelf sea in Mexico because of its large tidal range and fast tidal currents, of up to $8 \mathrm{~m}$ and $1 \mathrm{~ms}^{-1}$, respectively. The tides are dominated by the semi-diurnal components. The strong tidal forcing leads to large values of tidal dissipation (up to $0.5 \mathrm{~W} \mathrm{~m}^{-2}$ ) [Carbajal and Backhaus, 1998; Argote et al., 1995]. This large dissipation is responsible for the westward displacement of the amphidromic point in the central Gulf.

[5] Hydrographic observations and numerical modeling results suggest that tidal stirring is primarily responsible for the mixing of the water in the shallow part of the northern Gulf which develops a tidal mixing front where the Simpson and Hunter parameter $\left(S H=\log _{10}\left(h U^{-3}\right)\right)$ is between 2.5 and 3; higher values of $\mathrm{SH}$ generally correspond with stratified water columns [Carbajal et al., 1997; Argote et al., 1995]. There is a strikingly strong correlation between the position of the tidal mixing front and a front of surface SPM concentration as reported by Carbajal et al. [1997]. This persistent feature in surface SPM distribution suggests that suspended materials are mainly comprised of fine particles with specific concentrations being determined by turbulent tidal processes and associated resuspension. This has also been corroborated by SPM observations during spring tides [Alvarez and Jones, 2002].

[6] The present study builds on the observations of Alvarez and Jones [2002], and enhances the understanding of the tidal SPM resuspension by combining turbulence variables, specifically Reynolds stresses and turbulent kinetic energy (TKE) production, with concurrent measurements of SPM concentration. The present observations show predominant quarter-diurnal variability in TKE production and SPM resuspension. These parameters show pronounced lags between bottom and surface values. We explore both the nature of the separate lags and their interrelationships to explain the nature of the governing mechanisms.

\section{Methods}

[7] An Acoustic Doppler Current Profiler (ADCP) was deployed during the spring tidal period, between 27 and 
29 May 2002 at a site located at approximately $31^{\circ} 09.5^{\prime} \mathrm{N}$, $114^{\circ} 39.5^{\prime} \mathrm{W}$ with a mean water depth of about $25 \mathrm{~m}$, which is within the mixed region of the Upper Gulf of California. The ADCP (1200 kHz RDI Work Horse) operated in mode 1 and was set to record a 6 acoustic ping average every 2 seconds. A 10-minute window was used to calculate the mean velocities and Reynolds stresses, which were calculated following the variance method first described by Lohrmann et al. [1990] and later utilized by Stacey et al. [1999] and Rippeth et al. [2002]. The method relies upon the use of the ADCP's two pairs of opposing acoustic beams; each beam measures a velocity that is actually a weighted sum of the local horizontal and vertical velocities. For example, if beams 3 and 4 are chosen as one set of opposing beams, it follows that the velocities determined for beams 3 and $4\left(u_{3}\right.$ and $\left.u_{4}\right)$ are given by:

$$
u_{3}=u \sin \theta+w \cos \theta \quad \text { and } \quad u_{4}=-u \sin \theta+w \cos \theta
$$

where $\theta$ is the angle from the vertical $\left(20^{\circ}\right.$ in this case) and $(u, v)$ and $w$ are the horizontal and vertical velocity components, respectively. By separating the velocities into mean and fluctuating quantities and taking the difference between the two opposing beams it can be shown that turbulent Reynolds stresses take the form

$$
\overline{u^{\prime} w^{\prime}}=\frac{\operatorname{var}\left(u_{3}\right)-\operatorname{var}\left(u_{4}\right)}{4 \sin \theta \cos \theta} \text { and } \overline{v^{\prime} w^{\prime}}=\frac{\operatorname{var}\left(u_{1}\right)-\operatorname{var}\left(u_{2}\right)}{4 \sin \theta \cos \theta}
$$

where the overbars indicates the temporal means and primes indicate temporal fluctuations. The rate of production of TKE $(P)$, in $\mathrm{W} \mathrm{m}^{-3}$ is estimated from the product of the Reynolds stresses and the velocity shear according to:

$$
P=-\rho\left(\overline{u^{\prime} w^{\prime}} \frac{\partial \bar{u}}{\partial z}+\overline{v^{\prime} w^{\prime}} \frac{\partial \bar{v}}{\partial z}\right)
$$

where $\rho$ is the water density and $z$ is the vertical coordinate. Using this method we can also estimate the value of eddy viscosity, $N_{z}$, as:

$$
\frac{\tau_{x}}{\rho}=N_{z} \frac{\partial u}{\partial z}=\overline{u^{\prime} w^{\prime}} \quad \text { and } \quad \frac{\tau_{y}}{\rho}=N_{z} \frac{\partial v}{\partial z}=\overline{v^{\prime} w^{\prime}}
$$

where $\tau_{x}$ and $\tau_{y}$ are the eastward and northward components of stress. For a more detailed explanation of the variance method, refer to Stacey et al. [1999], Lu and Lueck [1999], and Rippeth et al. [2002].

[8] The 10-minute averaged acoustic signal strength recorded by the ADCP was converted to decibels. The signal was corrected for water sound absorption and geometric spreading as described by Deines [1999]. The corrected signal strength from the four beams was averaged; these data were then calibrated using vertical SPM profiles collected every half hour during 28 May 2002 using an Optical Backscatter System (OBS), which was calibrated with water samples. The linear regression between SPM concentration and acoustic backscatter produced the following relation:

$$
10 \log _{10} C=21+0.25 B
$$

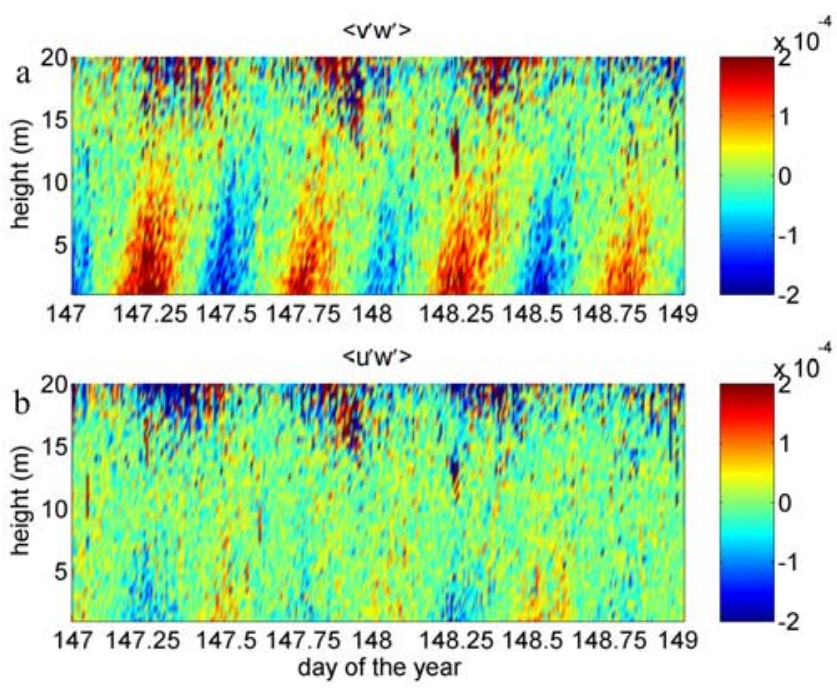

Figure 1. Reynolds stresses (a) north-south; (b) east-west in $\mathrm{m}^{2} \mathrm{~s}^{-2}$.

where $\mathrm{C}$ is the SPM concentration in $\mathrm{g} \mathrm{m}^{-3}$ and $B$ is the acoustic backscatter signal in $\mathrm{dB}$. This backscatter-concentration regression explains almost $86 \%$ of the variance.

\section{Observations}

[9] During the observational period, the tidal velocities were almost rectilinear with a semi-major axis of the order of $0.6 \mathrm{~m} \mathrm{~s}^{-1}$ near the sea surface and $0.3 \mathrm{~m} \mathrm{~s}^{-1}$ near bottom, while the near bottom and near surface tidal shears were 0.03 and $0.01 \mathrm{~s}^{-1}$, respectively. Figure 1 shows contours of Reynolds stresses for the north-south (Figure 1a) and east-west (Figure 1b) components and indicates tidal variation in turbulence. It is evident that the dominant component of the Reynolds stress lies close to the northsouth direction with maximum values of the order of $\pm 2 \times$ $10^{-4} \mathrm{~m}^{2} \mathrm{~s}^{-2}$, while the maximum east-west component values reach only about $\pm 5 \times 10^{-5} \mathrm{~m}^{2} \mathrm{~s}^{-2}$. The data tend to show an increase from a maximum value near the bottom $(\sim 1 \mathrm{mab})$ and decreases towards the surface with a minimum at about 12 mab. The maximum Reynolds stress appears to propagate progressively upwards during the beginning of the flood or ebb and decreases more rapidly towards slack water periods, thus producing a saw-tooth time-series. There also appears to be an asymmetry between flood and ebb, with higher stresses and greater penetration up into the water column during ebb (positive values) than during flood (negative values). Another interesting asymmetric feature is the presence of large values of Reynolds stresses near the surface at low water.

[10] The rate of production of TKE $(P)$ has been estimated following equation (3) with contoured values shown in Figure $2 \mathrm{a}$. As expected, the highest rate of TKE production is found near the bed with values decreasing about an order of magnitude between the bottom and $12 \mathrm{mab}$ (Figure 2a). The near-bed $(\sim 1.5 \mathrm{mab})$ maximum $P$ is of the order of $10^{-2} \mathrm{~W} \mathrm{~m}^{-3}$ during both ebb and flood with minimum values at slack water of the order of $10^{-4} \mathrm{~W} \mathrm{~m}^{-3}$. The bottom production $\mathrm{P}$ shows a quarter-diurnal periodicity as it is dependent on the current speed, i.e., there are two 


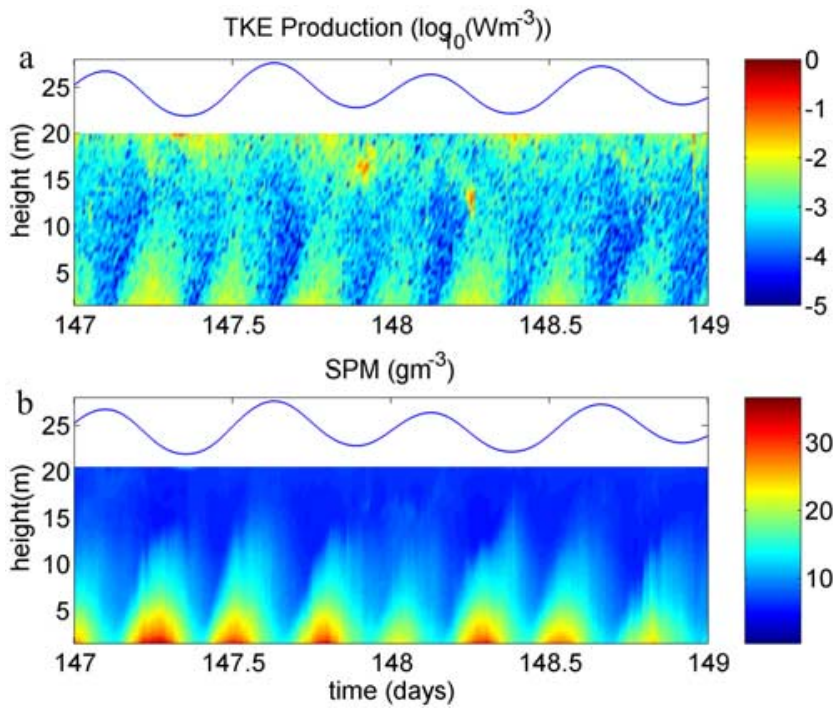

Figure 2. TKE production in $\mathrm{W} \mathrm{m}^{-3}$ (a) and SPM concentrations in $\mathrm{mg}^{-1}$ (b).

maxima of current speed per semi-diurnal tidal cycle. As is the case for the Reynolds stresses, there is an apparent asymmetry between flood and ebb, with higher values of $P$ and greater extension up into the water column during ebb. We can also observe maximum values of $P$ near the surface at low water slack. This is probably due to convection which derives from the tidal straining of denser water at the head of the Gulf (similar to Liverpool Bay [Rippeth et al., 2001]), as the sea was calm and we would not expect to observe wave-generated turbulence.

[11] Similar to TKE production, the concentration of SPM (Figure 2b) shows a quarter-diurnal variability with maxima of more than $30 \mathrm{~g} \mathrm{~m}^{-3}$ near the bottom, decreasing to less than $10 \mathrm{~g} \mathrm{~m}^{-3}$ at about $12 \mathrm{mab}$. The SPM concentration also appears to have a similar asymmetry in the near bottom region, but there is no sign of the near-surface localized maxima observed for $P$ at low water.

[12] Estimates of eddy viscosity $\left(N_{z}\right)$ were calculated from hourly averages of Reynolds stresses and shear following equation (4). These estimates of eddy viscosity (Figure 3a) show variability between $10^{-3}$ and $10^{-2} \mathrm{~m}^{2} \mathrm{~s}^{-1}$ in the bottom half of the water column, with maximum values around peak flow and low values around slack water. We also estimated the eddy viscosity from the regression of all the estimates of Reynolds stress and shear (Figure 3b); this is equivalent to the mean vertical profile of $N_{z}$. The mean eddy viscosity shows a typical profile with values slightly increasing from the bottom $\left(\sim 3 \times 10^{-3} \mathrm{~m}^{2} \mathrm{~s}^{-1}\right)$ to about $3.8 \times 10^{-3} \mathrm{~m}^{2} \mathrm{~s}^{-1}$ at about $3 \mathrm{mab}$ followed by a continuous decrease to near zero at $12 \mathrm{mab}$.

\section{4. $\mathrm{M}_{4}$ Tidal Components of TKE and SPM}

[13] To better quantify the tidal influence in the TKE and SPM dynamics, we have carried out an $\mathrm{M}_{4}$ harmonic analysis for the 48 hours of data shown. The TKE production (Figures $4 \mathrm{a}$ and $4 \mathrm{~b}$ ) shows an exponential decrease from $4 \times$ $10^{-3} \mathrm{~W} \mathrm{~m}^{-3}$ near the bottom to about $3 \times 10^{-4} \mathrm{~W} \mathrm{~m}^{-3}$ at about $12 \mathrm{mab}$; the phase lag within the same distance is about $60^{\circ}(\sim 1$ hour). The SPM harmonic analysis
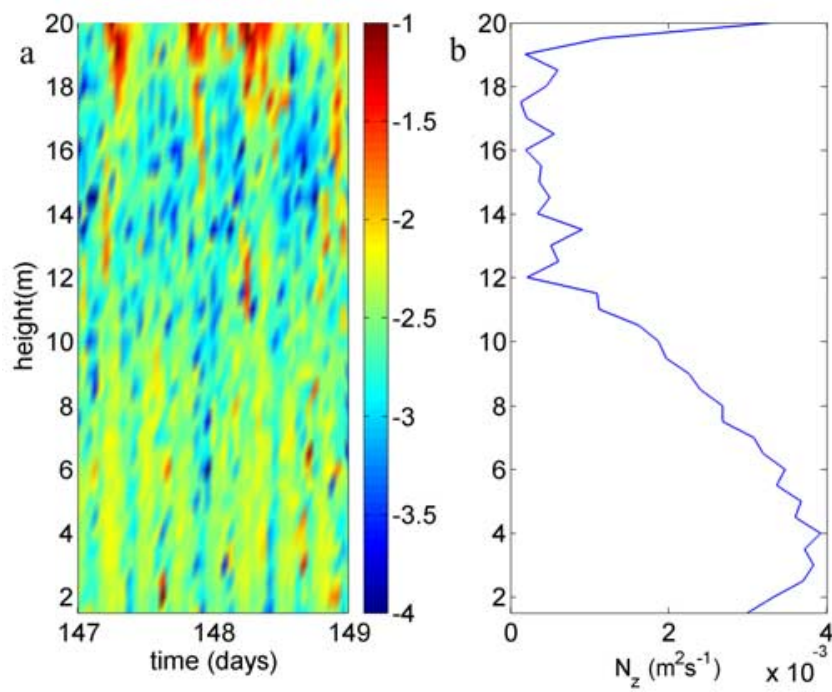

Figure 3. Estimates of eddy viscosity $N_{z}$ in $\mathrm{m}^{2} \mathrm{~s}^{-1}$. (a) time series of vertical distribution of $\log _{10}\left(N_{z}\right)$; (b) mean profile of $N_{z}$.

(Figures $3 \mathrm{c}$ and $3 \mathrm{~d}$ ) indicates an exponential decrease between $8.5 \mathrm{~g} \mathrm{~m}^{-3}$ near bottom to almost zero near the surface, while the phase lag between surface and bottom is about $180^{\circ}$. If we confine our inspection of the changes in SPM to the region where the TKE is dominated by tidal forcing, i.e., the bottom $12 \mathrm{~m}$ of the water column, we note that the SPM concentration reduces from 8 to $2 \mathrm{~g} \mathrm{~m}^{-3}$ and the phase lag is about $90^{\circ}(\sim 1.5$ hours $)$. Another important result of this analysis is that there is a time lag of about half an hour between maximum TKE production and maximum SPM resuspension near the bottom for both tidal cycles.

[14] Noting from the previous section that The $N_{z}$ profile shows a more or less constant value of $3.5 \times 10^{-3} \mathrm{~m}^{2} \mathrm{~s}^{-1}$ between near the bed and 7 mab we attempt to explain the vertical variations in $\mathrm{M}_{4}$ values of TKE and SPM using a model which assumes a constant eddy viscosity. Based on this assumption, the bottom variability can be explained
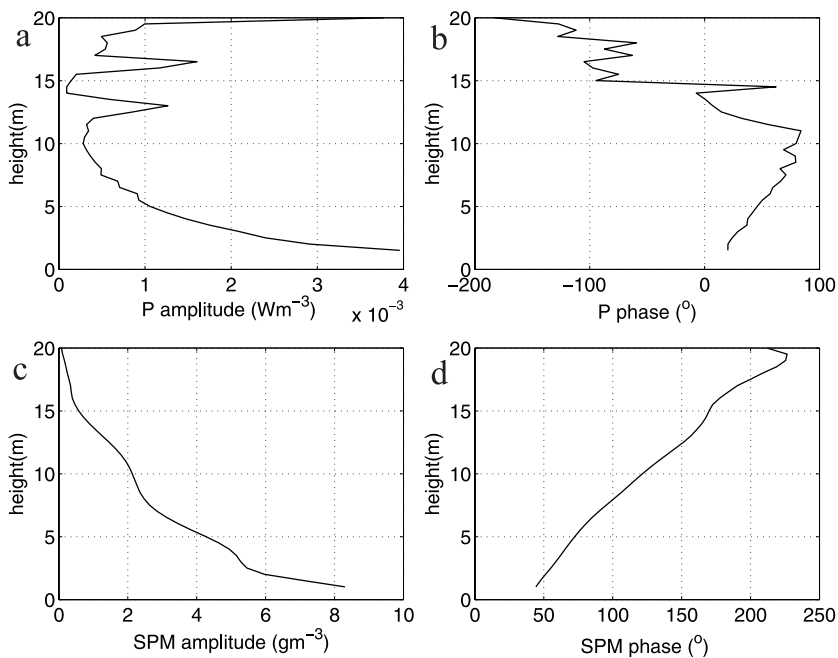

Figure 4. $\mathrm{M}_{4}$ harmonic analysis. (a) TKE production amplitude in $\mathrm{W} \mathrm{m} \mathrm{m}^{-3}$; (b) TKE production phase in ${ }^{\circ}$; (c) SPM amplitude in $\mathrm{g} \mathrm{m}^{-3}$ and (d) SPM phase in ${ }^{\circ}$. 
following Simpson et al. [2000] where the rate of TKE production $(P)$ is given by:

$$
P=\rho N_{z}\left(\frac{\partial u}{\partial z}\right)^{2}=\frac{\rho N_{z} A^{2} \beta^{2}}{\omega^{2}} e^{-2 \beta z}\left(1+\cos \left(2 \omega t-2 \beta z-\frac{\pi}{2}\right)\right)
$$

where $\rho$ is the water density; $N_{z}$ is the eddy viscosity; $A$ is the amplitude of the local tidal slope; $\omega$ is the semi-diurnal frequency $\left(\mathrm{M}_{2}\right)$ and $\beta=\left(\omega / 2 N_{z}\right)^{1 / 2}$. The production $(\mathrm{P})$ has a quarter-diurnal variation and the vertical phase lag is given by:

$$
\varphi=2 \beta z+\frac{\pi}{2}=\sqrt{\frac{2 \omega}{N_{z}}} z+\frac{\pi}{2}
$$

Based on our observations, it can be noted that there is a lag of about $\pi / 3$ between the bottom and $7 \mathrm{mab}$; this translates to a value of $N_{z}$ of about $10^{-2} \mathrm{~m}^{2} \mathrm{~s}^{-1}$, which is in good agreement with the estimated values of $N_{z}$ during high flows.

[15] The vertical variation of SPM can be explained using Fickian diffusion principles as described by Prandle [1997], and applying the following equation:

$$
C(z, t)=\frac{M}{\left(4 \pi N_{z} t\right)^{1 / 2}}\left[e^{\frac{-\left(z+w_{s} t\right)^{2}}{4 N_{z} t}}+e^{\frac{-\left(2 D+w_{s} t-z\right)^{2}}{4 N_{z} t}}\right]
$$

where $w_{s}$ is the sediment settling velocity; $\mathrm{D}$ is the water depth and $M$ is the erosion function, which is assumed to be proportional to the bottom stress or to the bottom TKE production. Exploratory numerical studies showed good qualitative agreement with the observations by prescribing values of settling velocity and eddy diffusivity that are allowed to vary in the ranges between 0.1 and $1 \mathrm{~mm} \mathrm{~s}^{-1}$ and $10^{-3}$ and $10^{-2} \mathrm{~m}^{2} \mathrm{~s}^{-1}$, respectively. Figure 5 shows a comparison between the observations and the results of equation (8) for the bottom 7 meters of the water column. The model incorporates a value of $w_{s}$ of $0.3 \mathrm{~mm} \mathrm{~s}^{-1}$ and values of $N_{z}$ of $3 \times 10^{-3}$ and $10^{-2} \mathrm{~m}^{2} \mathrm{~s}^{-1}$, i.e., the mean and maximum values from the initial estimates. The model reproduces the observed decrease of the $M_{4}$ SPM concentration amplitudes and delay in phases relative to the bottom. Good agreement between observations and theory is found within the envelope of the indicated values of $N_{z}$.

[16] Equation (8) can also explain the behavior of turbulence if we neglect the second term on the right hand side (reflection from the surface), set $w_{s}$ to zero and we include a decay rate $\mathrm{e}^{-\mathrm{t} / \mathrm{T}}$, where $\mathrm{T}$ is the half-life time of the turbulence. Figure 5 shows the comparison between theory and observations using a half-life of 1 hour, it is interesting that the theory fits better for the mean eddy viscosity value of $3 \times 10^{-3} \mathrm{~m}^{2} \mathrm{~s}^{-1}$.

\section{Conclusions}

[17] This work advances the understanding of turbulence generation and dissipation and SPM dynamics by the following.

[18] 1. Demonstrating the capability to continuously and simultaneously measure TKE production and SPM using a single instrument, combining the variance method [Stacey et
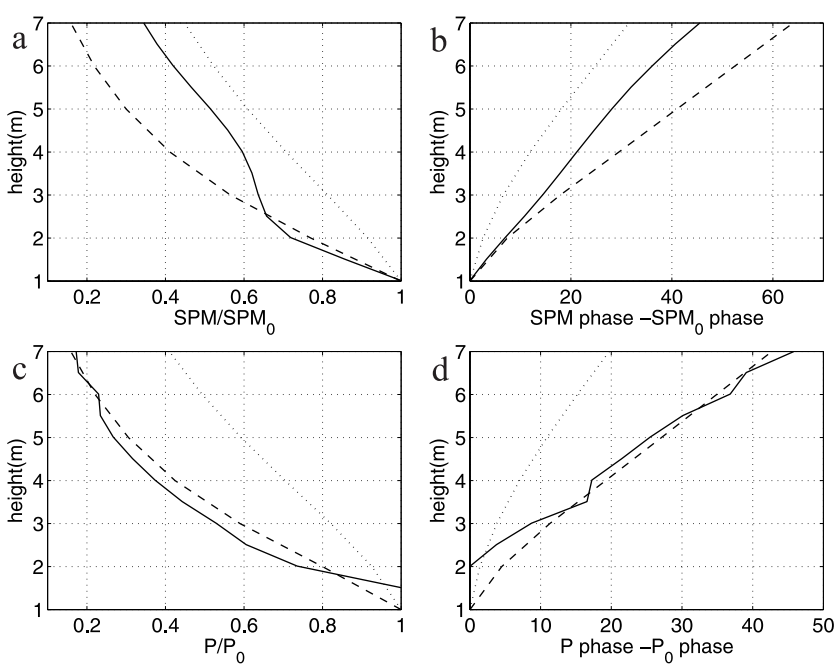

Figure 5. Comparisons of observed and theoretical distributions of SPM and TKE production. (- -) assumes an eddy viscosity value of $3 \times 10^{-3}$ and (...) assumes a value of $10^{-2} \mathrm{~m}^{2} \mathrm{~s}^{-1}$. (a) and (b) are the comparison of the $\mathrm{M}_{4}$ amplitudes and phases of SPM, respectively and use a settling velocity of $0.3 \mathrm{~mm} \mathrm{~s}^{-1}$. (c) and (d) show the $M_{4}$ amplitudes and phases for TKE production using a half-life of 1 hour. Note that the amplitudes are normalized by the value of the bottom amplitude and the phases are relative to the bottom phase.

al., 1999; Rippeth et al., 2002] and acoustic backscatter measurements to estimate SPM.

[19] 2. Illustrating good agreement between these observations and classical theoretical studies of turbulence and SPM [e.g., Simpson et al., 2000; Prandle, 1997].

[20] To our knowledge, this is the first complete data set that combines measurements of turbulence characteristics, such as TKE production and Reynolds stresses, and SPM concentrations in shelf seas. As such, it offers simple and exciting opportunities, applicable in a wide range of conditions, to test and develop turbulence and SPM models and thereby improve our predictive capabilities.

[21] Acknowledgments. This work was funded through the collaborative program UC-MEXUS/CONACYT/CICESE for the Colorado River Delta and Upper Gulf of California (grants to Luis Alvarez and Tommy Dickey). A. Souza's work was partially funded by the UK NERC under grant NER/M/S/2002/00076 and by ONRIFO VSP grant N00014-02-14031. The authors would also like to thank Dave Prandle for his help and support in improving this article.

\section{References}

Alvarez, L. G. (2003), Suspended sediment dynamics in the Upper Gulf of California, Ph.D. thesis, 175 pp., Univ. of Wales, Bangor, U. K.

Alvarez, L. G., and S. E. Jones (2002), Factors influencing suspended sediment flux in the Upper Gulf of California, Estuarine Coastal Shelf. Sci., 54, 747-759.

Argote, M. L., A. Amador, M. F. Lavin, and J. R. Hunter (1995), Tidal dissipation and stratification in the Gulf of California, J. Geophys. Res., 100, 16,103-16,118.

Carbajal, N., and J. O. Backhaus (1998), Simulation of tides, residual flow and energy budget in the Gulf of California, Oceanol. Acta, 21, 429-446. Carbajal, N., A. J. Souza, and R. Durazo (1997), A numerical study of the ex-ROFI of the Colorado river, J. Mar. Syst., 12, 17-33.

Carriquiry, J. D., and A. Sanchez (1999), Sedimentation in the Colorado River delta and Upper Gulf of California after nearly a century of discharge loss, Mar. Geol., 158, 125-145. 
Deines, K. L. (1999), Backscatter estimation using broadband acoustic Doppler current profilers, in Proceedings of the IEEE/OES 6th Working Conference on Current Measurement Technology, pp. 259-264, Inst. of Electr. and Electr. Eng., Piscataway, N. J.

Lohrmann, A., B. Hackett, and L. P. Roed (1990), High resolution measurements of turbulence, velocity and stress using pulse-to-pulse coherent sonar, J. Oceanic Atmos. Technol., 7, 19-37.

Lu, Y, and R. G. Lueck (1999), Using a broadband ADCP in a tidal channel. Part II: Turbulence, J. Oceanic Atmos. Technol., 16, 1568-1579.

Prandle, D. (1997), Tidal characteristics of suspended sediment concentrations, J. Hydraul. Eng., 123, 341-350.

Rippeth, T. P., N. R. Fisher, and J. H. Simpson (2001), The cycle of turbulent dissipation in the presence of tidal straining, J. Phys. Oceanogr., $31,2458-2471$.

Rippeth, T. P., E. Williams, and J. H. Simpson (2002), Reynolds stress and turbulent energy production in a tidal channel, J. Phys Oceanogr., 32, $1242-1251$.
Simpson, J. H., T. P. Rippeth, and A. R. Campbell (2000), The phase lag of turbulent dissipation in tidal flow, in Interactions Between Estuaries, Coastal Seas and Shelf Seas, edited by T. Yanagi, pp. 57-67, Terrapub, Tokyo.

Stacey, M. T., S. T. Monismith, and J. R. Burau (1999), Measurements of Reynolds stress in unstratified tidal flow, J. Geophys. Res., 104, 10,93310,949 .

L. G. Alvarez, Departamento de Oceanografia Fisica, CICESE, 22860 Ensenada, Mexico.

T. D. Dickey, Ocean Physics Laboratory, University of California, 6487 Calle Real/Unit A, Santa Barbara, CA 93117, USA.

A. J. Souza, Proudman Oceanographic Laboratory, 6 Brownlow Street, Liverpool L3 5DA, UK. (ajso@pol.ac.uk) 